\title{
Case of Bullous Impetigo Developing into Staphylococcal Scalded Skin Syndrome: Case Report
}

Elharrouni $\mathrm{A}^{1^{*}}$, Elimam $\mathrm{M}^{2}$, Dassouly $\mathrm{R}^{1}$, Hnach $\mathrm{KH}^{2}$, Elloudi $\mathrm{S}^{1}$, Douhi $\mathrm{Z}^{1}$, Baybay $\mathrm{H}^{1}, \mathrm{Hida}^{2}$, Mernissi FZ ${ }^{1}$

${ }^{1}$ Department of Dermatology, CHU Hassan II, FEZ, Morocco

${ }^{2}$ Department of Paediatrics, CHU Hassan II, FEZ, Morocco

Corresponding Author: Elharrouni Alaoui Aicha

Address: Department of Dermatology, CHU Hassan II, FEZ, Morocco; E-mail: ealaouiaicha@gmail.com

Received date: 29 September 2019; Accepted date: 22 October 2019; Published date: 06 December 2019

Citation: Elharrouni A, Elimam M, Dassouly R, Hnach KH, Elloudi S, Douhi Z, Baybay H, Hida M, Mernissi FZ. Case of Bullous Impetigo Developing into Staphylococcal Scalded Skin Syndrome: Case Report. J Health Care and Research. 2019 Dec 06;1(1):4-6.

Copyright (C) 2019 Elharrouni A, Elimam M, Dassouly R, Hnach KH, Elloudi S, Douhi Z, Baybay H, Hida M, Mernissi FZ. This is an open-access article distributed under the Creative Commons Attribution License, which permits unrestricted use, distribution, and reproduction in any medium, provided the original work is properly cited.

\section{Abstract}

Staphylococcus aureus can cause exfoliative skin conditions, ranging from localized bullous impetigo (BI) to staphylococcal scalded skin syndrome (SSSS). The latter is a potentially life-threatening disorder, which leads to blistering of the upper layer of the skin, by the release of a circulating exotoxin. The disease especially affects infants and small children but has also been described in adults. SSSS usually presents with a prodrome of sore throat or conjunctivitis. The infection is often peri-facial impetigo, here is usually no bacteremia. Bullous impetigo, the toxin produces blisters locally at the site of infection, whereas in cases of the scalded-skin syndrome, it circulates throughout the body, causing blisters at sites distant from the infection.

\section{Keywords}

Staphylococcal Skin Infections; Bullous Impetigo; Staphylococcal Scalded Skin Syndrome; Immunocompetent Infant

\section{Introduction}

Staphylococcal skin infections are among the most common skin diseases in children. Staphylococcal scalded skin syndrome (SSSS) is a common disorder that is usually seen in infants and children and rarely seen in adults. It is caused by exfoliative toxin released by staphylococcus.Diagnosis is based on clinical examination but it can be confirmed by a skin biopsy specimen. Prompt therapy with proper antibiotics and supportive treatment has led to a decrease in the mortality rate [1]. We report a case of bullous impetigo developing into staphylococcal scalded skin syndrome in immunocompetent infant.

\section{Case report}

An 11month-old infant presented with a Fragile bullae develops within the erythematous areas that extend to large sheets of epidermal detachment, beginning on the central face axillae, groin, neck, inguinal areas, and black. The lesion started as a small macule with the areas dry with a thin, shiny crust and fissures in perioral and periorbital skin 4 days prior, which turned into a bulla and enlarged over 2 days, associated with a fever at $39 c^{\circ}$. There was no known medical history of trauma or burn. On physical examination, a large erosive area with a thin, shiny crust and fissures in perioral, 
Citation: Elharrouni A, Elimam M, Dassouly R, Hnach KH, Elloudi S, Douhi Z, Baybay H, Hida M, Mernissi FZ. Case of Bullous Impetigo Developing into Staphylococcal Scalded Skin Syndrome: Case Report. J Health Care and Research. 2019 Dec 06;1(1):4-6.

periorbital, perianal and postauricular, skin detachment involving $>50 \%$ of the total body surface area with positive Nikolsky sign, but the mucosal surfaces were not involved. Bullous impetigo, staphylococcal scalded skin syndrome (SSSS) and toxic epidermal necrolysis were raised as possible diagnoses. Swab/tissue cultures have performed, the results yielded amoxicillin-susceptible Staphylococcus aureus, as well as punch biopsy has performed after hospitalization, revealed acantholysis at the upper spinous and granular layer with polymorphous infiltrates at the upper dermis. These findings, we diagnosed bullous impetigo developing into staphylococcal scalded skin syndrome. Intravenous amoxicillin+clavunalic acid (50mg/kg per day) and local supportive care resulted in quick improvement with complete reepithelialization in 10 days(Fig-1a-f).

\section{Discussion}

Staphylococcus aureus is often responsible for late septic infections, more rarely of toxic ones, occurring in neonatal period [2,3]. Although bullous impetigo and SSSS are considered as a spectrum of disease caused by staphylococcus aureus induced exfoliative toxins, they have distinct differences [2,3]. In bullous impetigo, the exfoliative toxins are restricted to the area of infection, and bacteria can be cultured from the blister contents. In staphylococcal scalded skin syndrome the exfoliative toxins are spread hematogenously from a localized source causing widespread epidermal damage at distant sites $[4,5]$. The lesions of bullous impetigo are commonly seen on the face, trunk and extremities which are vesicles to begin with and later becoming pus-filled, followed by rupture and crusting. The lesional bacterial culture reveals S. aureus. Nikolsky's sign, a disruption of normal skin caused by mechanical stress, is negative. In SSSS The diagnosis is mainly a)

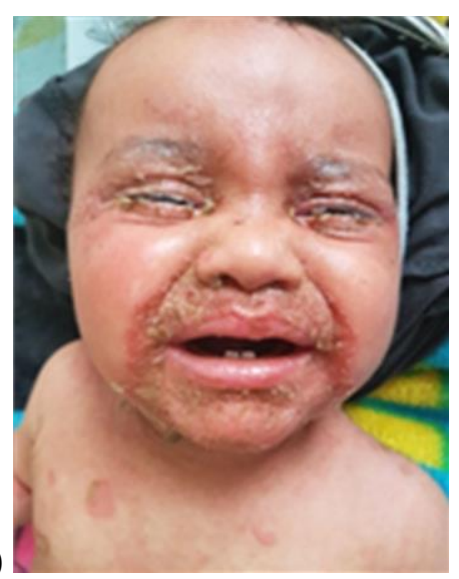

b)

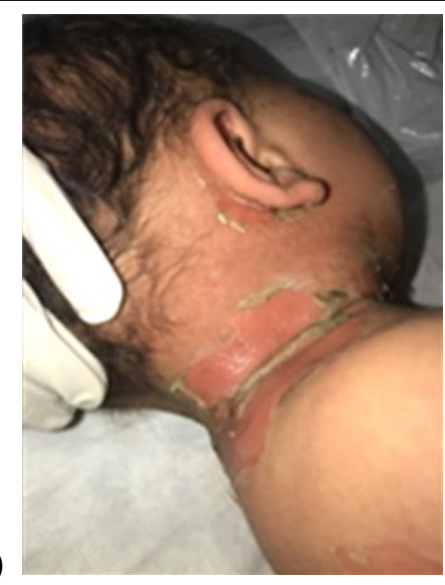

c)
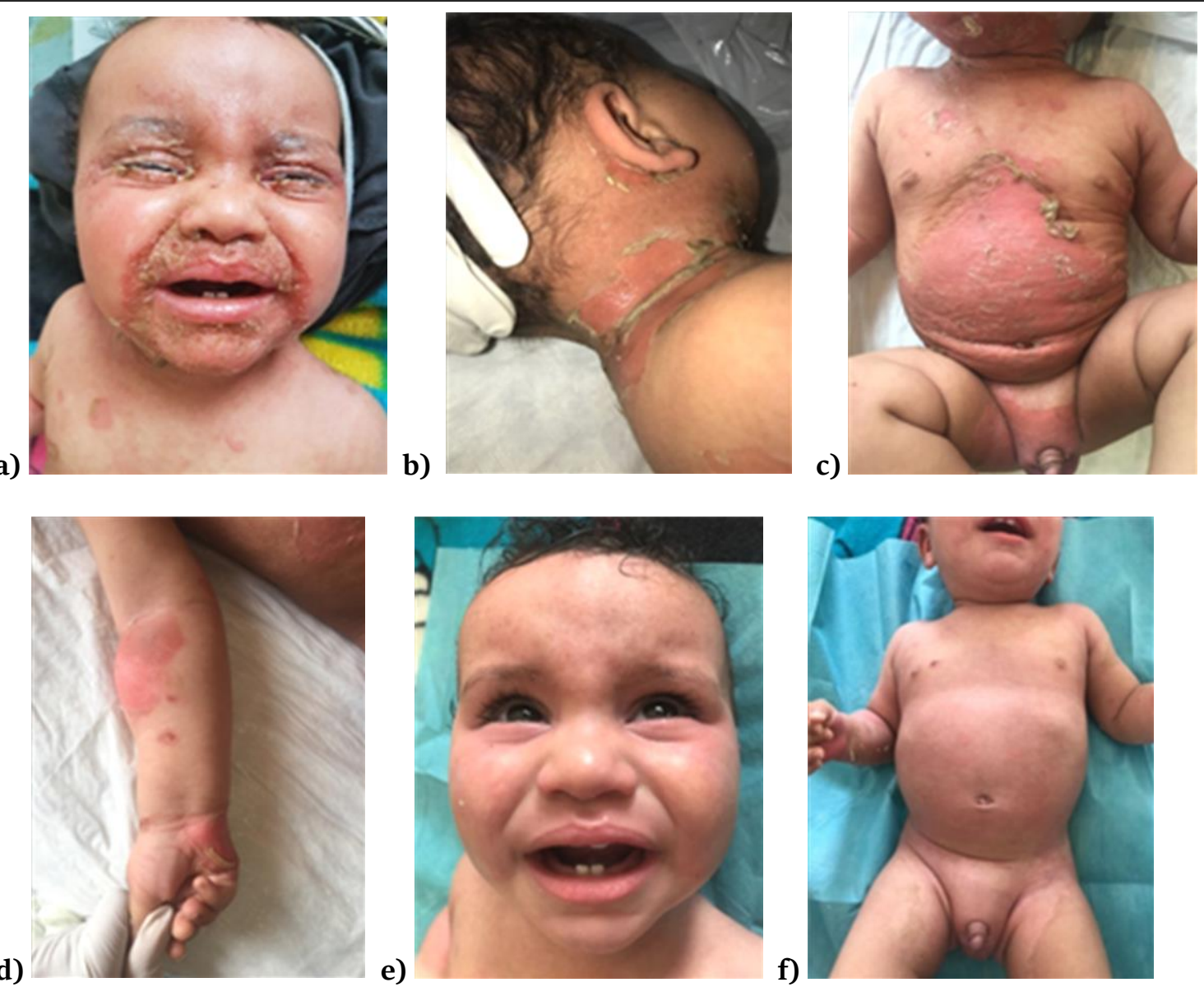

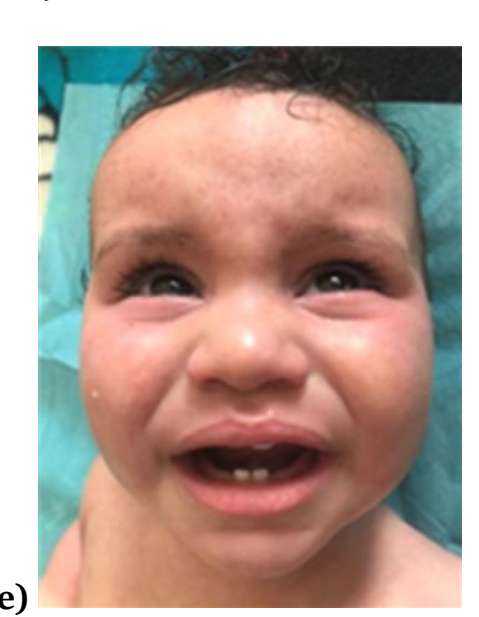

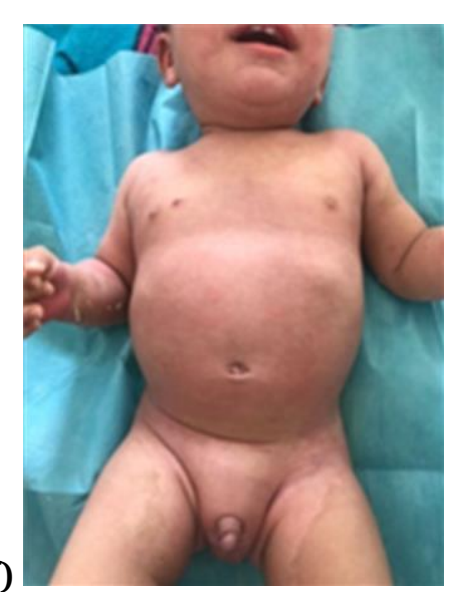

Fig-1a-f:

11 month infant presents with a large erosive area with a thin, shiny crust and fissures in perioral,periorbital,perianal and postauricular, skin detachment involving $>50 \%$ of the total body surface area with positive Nikolsky(a.b.c.d). And l'evolution : complete re-epithelialization within 1odays (e.f) 
Citation: Elharrouni A, Elimam M, Dassouly R, Hnach KH, Elloudi S, Douhi Z, Baybay H, Hida M, Mernissi FZ. Case of Bullous Impetigo Developing into Staphylococcal Scalded Skin Syndrome: Case Report. J Health Care and Research. 2019 Dec 06;1(1):4-6.

Case Report

clinical, based on the findings of tender erythroderma, bullae, and desquamation with a scalded appearance especially in friction zones, periorificial scabs/crusting, positive Nikolsky sign, and absence of mucosal involvement $[4,5]$. The diagnosis can be confirmed by culturing S.aureus from any suspected primary focus of infection, but A skin biopsy is usually not necessary, but if performed, may show superficial intraepidermal separation along the granular cell layer $[6,7]$. In our patient, bullous impetigo was characterized by isolation of S.aureus and by histological findings. However, there was no case of extensive bullous impetigo followed by SSSS in neonates, as far as we know. Once SSSS is diagnosed, the treatment consists of supportive care and eradication of the primary infection with antistaphylococcal antibiotics administered by vein for a minimum of seven days [8]. Bullous impetigo and staphylococcal scalded skin syndrome have a different prognosis.

\section{Conclusion}

In conclusion, clinicians should be aware, although not frequent, that bullous impetigo may progress to SSSS which differs in mortality and close observation is required whenever suspicious.

\section{References}

[1] Menon NS. Staphylococcal scalded skin syndrome case series with review of literature. IAIM. 2015;2:21419.

[2] Amagai M, Matsuyoshi N, Wang ZH, Andl C, Stanley JR. Toxin in bullous impetigo and staphylococcal scalded-skin syndrome targets desmoglein 1. Nat Med. 2000 Nov;6(11):1275-77. [PMID: 11062541]

[3] Plano LR, Adkins B, Woischnik M, Ewing R, Collins CM. Toxin levels in serum correlate with the development of staphylococcal scalded skin syndrome in a murine model. Infect Immun. 2001 Aug;69(8):5193-97. [PMID: 11447206]

[4] Mockenhaupt M, Idzko M, Grosber M, Schöpf E, Norgauer J. Epidemiology of staphylococcal scalded skin syndrome in Germany. J Invest Dermatol. 2005 Apr;124(4):700-3. [PMID: 15816826]

[5] Hubiche T, Bes M, Roudiere L, Langlaude F, Etienne J, Del Giudice P. Mild staphylococcal scalded skin syndrome: an underdiagnosed clinical disorder. Br J Dermatol. 2012 Jan;166(1):213-15. [PMID: 21729032]

[6] Lasek-Duriez A, Léauté-Labrèze C, la Société franc, aise de dermatopédiatrie. Signes cutanés des sévices à enfants (à l'exclusion des sévices sexuels). Ann Dermatol Venereol. 2009 Oct;136(11):838-44.

[7] Courjon J, Hubiche T, Phan A, Tristan A, Bès M, Vandenesch F, Etienne J, Del Giudice P, Gillet Y. Skin findings of Staphylococcus aureus toxin-mediated infection in relation to toxin encoding genes. Pediatr Infect Dis J. 2013 Jul;32(7):727-30. [PMID: 23446443]

[8] Lamand V, Dauwalder O, Tristan A, Casalegno JS, Meugnier H, Bes M, Dumitrescu O, Croze M, Vandenesch F, Etienne J, Lina G. Epidemiological data of staphylococcal scalded skin syndrome in France from 1997 to 2007 and microbiological characteristics of Staphylococcus aureus associated strains. Clin Microbiol Infect. 2012 Dec;18(12):E514-21. [PMID: 23078129] 